\title{
REVIEW \\ Posttransplant maintenance therapy in multiple myeloma: the changing landscape
}

\author{
S Sengsayadeth ${ }^{1,3}$, F Malard $^{2,3}$, BN Savani ${ }^{1}$, L Garderet $^{2}$ and M Mohty ${ }^{2}$
}

Transplant-eligible patients with multiple myeloma (MM) now have extended survival after diagnosis owing to effective modern treatment strategies that include new agents in induction therapy, autologous stem cell transplant (ASCT), consolidation therapy and posttransplant maintenance therapy. Standard of care for newly diagnosed, fit patients includes ASCT and, often nowadays, posttransplant maintenance. Several large studies have shown the efficacy of maintenance with thalidomide, lenalidomide and bortezomib in the treatment scheme of MM with regards to prolonging progression-free survival and, to a lesser degree, overall survival. Herein we discuss the data currently available to support the use of maintenance therapy in patients after ASCT as well as the newer available agents that may be a part of its changing landscape in the years to come.

Blood Cancer Journal (2017) 7, e545; doi:10.1038/bcj.2017.23; published online 24 March 2017

\section{INTRODUCTION}

In the past two decades, multiple myeloma (MM) has emerged from being an almost uniformly fatal hematological malignancy to one for which there is now a major arsenal of transformative new therapies. Before the turn of the century, the median survival after diagnosis for patients requiring therapy was approximately 3 years. ${ }^{1}$ In the current era of modern treatment, the median survival after induction chemotherapy and autologous stem cell transplant (ASCT) alone reached 7 years. ${ }^{1-3}$ High-dose chemotherapy with melphalan followed by ASCT remains one of the mainstays of treatment and is considered the standard of care for fit, eligible patients. ${ }^{4-8}$ Despite good response rates with ASCT with duration of response up to years after the procedure, relapses are almost inevitable for most patients, primarily due to incomplete eradication of residual myeloma cells. It is postulated that the depth of response to primary therapy is associated with improved outcomes, particularly in the setting of ASCT. ${ }^{9}$ Furthermore, achievement of complete response and in particular a minimal residual disease-negative state after autologous hematopoietic stem cell transplantation may translate into improved progression-free survival (PFS) and even overall survival (OS). ${ }^{10-14}$ Two different approaches have been developed to pursue treatment after induction therapy: consolidation and maintenance therapy. Consolidation is a short treatment, generally consisting of a single agent or combination therapy or a second autologous hematopoietic stem cell transplantation aimed to increase the depth of the response. Maintenance therapy is applied for a longer period, usually for 2-3 years or even until disease progression, in order to maintain the depth of the response. Per definition, maintenance must be a long-term treatment, therefore for the purpose of this review we defined posttransplant maintenance as treatment administered for at least 1 year. Maintenances administered $<1$ year should probably be considered as consolidation treatment and are not addressed in this review.

Although first maintenance attempts with conventional chemotherapy, steroids or interferon-alpha were disappointing, ${ }^{15-20}$ in recent years posttransplant maintenance using new agentsthalidomide, lenalidomide, bortezomib - to augment the posttransplant response and its duration has arguably been part of the standard of care for many patients after ASCT. ${ }^{9}$ Ideal agents for maintenance are those that are easily administered (for many, this entails being an oral drug) and induce minimal toxicity while maintaining the initial response to upfront therapy. Herein we look at the current data regarding maintenance therapy and discuss the newer emerging agents that may be incorporated in future posttransplant treatment strategies.

\section{THALIDOMIDE MAINTENANCE}

Thalidomide was the first of the novel drugs belonging to the class of immunomodulatory agents (IMIDs) to garner interest as potential post-ASCT maintenance. In the late 1990s, early phase studies showed that thalidomide antiangiogenesis properties had significant antitumor effects in $\mathrm{MM}^{21}$ and since then, thalidomide has been incorporated in induction regimens. ${ }^{22,23}$ Thereafter, several studies, as outlined in Table 1, have shown improvement in PFS and OS, albeit the latter to a lesser degree, when thalidomide is incorporated into maintenance therapy postASCT. ${ }^{2,24-29}$ Thalidomide, however, is associated with significant and often dose-limiting toxicity, with the predominant adverse effects being peripheral neuropathy and an increased risk for venous thromboembolic events. There are also data suggesting that thalidomide maintenance should not be offered to patients with poor-risk cytogenetics as determined by fluorescence in situ hybridization, as these patients have been shown to have inferior outcome compared with controls. ${ }^{26}$ Meta-analyses of thalidomide

\footnotetext{
${ }^{1}$ Section of Hematology and Stem Cell Transplant, Vanderbilt Ingram Cancer Center, Nashville, TN, USA and ${ }^{2}$ Department of Haematology, Saint Antoine Hospital, University Pierre and Marie Curie, and INSERM UMRs 938, Paris, France. Correspondence: Professor M Mohty, Service d'Hématologie Clinique et de Thérapie Cellulaire, Hôpital Saint Antoine, APHP, Université Pierre et Marie Curie and INSERM, UMRs 938, 184 rue du Faubourg Saint-Antoine, Paris 75012, France.

E-mail: mohamad.mohty@inserm.fr

${ }^{3}$ These authors contributed equally to this work and both should be considered as first authors.

Received 20 December 2016; accepted 31 January 2017
} 
Table 1. Major studies of thalidomide maintenance

\begin{tabular}{|c|c|c|c|c|c|}
\hline Study & $\mathrm{N}$ & Regimen & Duration & PFS & OS \\
\hline Attal et al..$^{23}$ & 597 & $\begin{array}{l}\text { No maintenance vs pamidronate vs } \\
\text { pamidronate+Thal } 400 \mathrm{mg}\end{array}$ & $\begin{array}{l}15 \text { months } \\
\text { median for Thal }\end{array}$ & $\begin{array}{l}36 \text { vs } 37 \text { vs } 52 \% \\
(P<0.009)\end{array}$ & $\begin{array}{l}77 \text { vs } 74 \text { vs } 87 \% \\
(P<0.04)\end{array}$ \\
\hline Barlogie et al. ${ }^{2,24}$ & 668 & $\begin{array}{l}\text { No Thal vs Thal maintenance } 100 \mathrm{mg} \\
\text { daily for first year, then } 50 \mathrm{mg} \text { QOD }\end{array}$ & Until progression & $\begin{array}{l}5 \text {-year PFS } \\
57 \text { (Thal) vs } 44 \% \text { (no treatment) } \\
P=0.0005\end{array}$ & $\begin{array}{l}68 \text { vs } 65 \% \\
P=0.04\end{array}$ \\
\hline Morgan et al. ${ }^{25}$ & 820 & Thal vs no Thal & Until progression & $\begin{array}{l}22 \text { vs } 15 \text { months } \\
P<0.0001\end{array}$ & $\begin{array}{l}60 \text { months in both the groups } \\
P=0.70\end{array}$ \\
\hline Lokhorst et al. $^{26}$ & 556 & $\begin{array}{l}\text { Thal } 50 \mathrm{mg} \text { vs interferon } 3 \text { million IU } \\
\text { TIW }\end{array}$ & Until progression & $\begin{array}{l}34 \text { vs } 25 \text { months } \\
P<0.001 \\
\mathrm{HR}=0.67,95 \% \mathrm{Cl}=0.55-0.82\end{array}$ & $\begin{array}{l}73 \text { vs } 63 \text { months } \\
P=0.77 \\
H R=0.96,95 \% \mathrm{Cl} 0.74-1.23\end{array}$ \\
\hline Stewart et al. ${ }^{27}$ & 332 & Thal/Pred vs no treatment & $\begin{array}{l}4 \text { years or until } \\
\text { progression }\end{array}$ & $\begin{array}{l}4-y e a r P F S \\
32 \text { vs } 14 \% \\
\mathrm{HR}=0.56 \\
P<0.0001\end{array}$ & $\begin{array}{l}\text { 4-year OS } \\
68 \text { vs } 60 \% \\
\mathrm{HR}=0.77 \\
P=0.18\end{array}$ \\
\hline Maiolino et al. ${ }^{28}$ & 108 & Dex vs Thal+Dex & $\begin{array}{l}12 \text { months or until } \\
\text { progression }\end{array}$ & $\begin{array}{l}\text { 2-year PFS } \\
30 \text { (D) vs } 64 \% \text { (TD) } \\
P=0.002 \\
\text { Median PFS } \\
19 \text { (D) vs } 36 \text { months (TD) }\end{array}$ & $\begin{array}{l}\text { 2-year OS } \\
70 \text { (D) vs } 85 \% \text { (TD) } \\
P=0.27\end{array}$ \\
\hline
\end{tabular}

Abbreviations: $\mathrm{Cl}$, confidence interval; Dex, dexamethasone; IU, international units; OS, overall survival; PFS, progression-free survival; Pred, prednisone; QOD, every other day; TIW, three times weekly; Thal, thalidomide.

Table 2. Major studies of lenalidomide maintenance

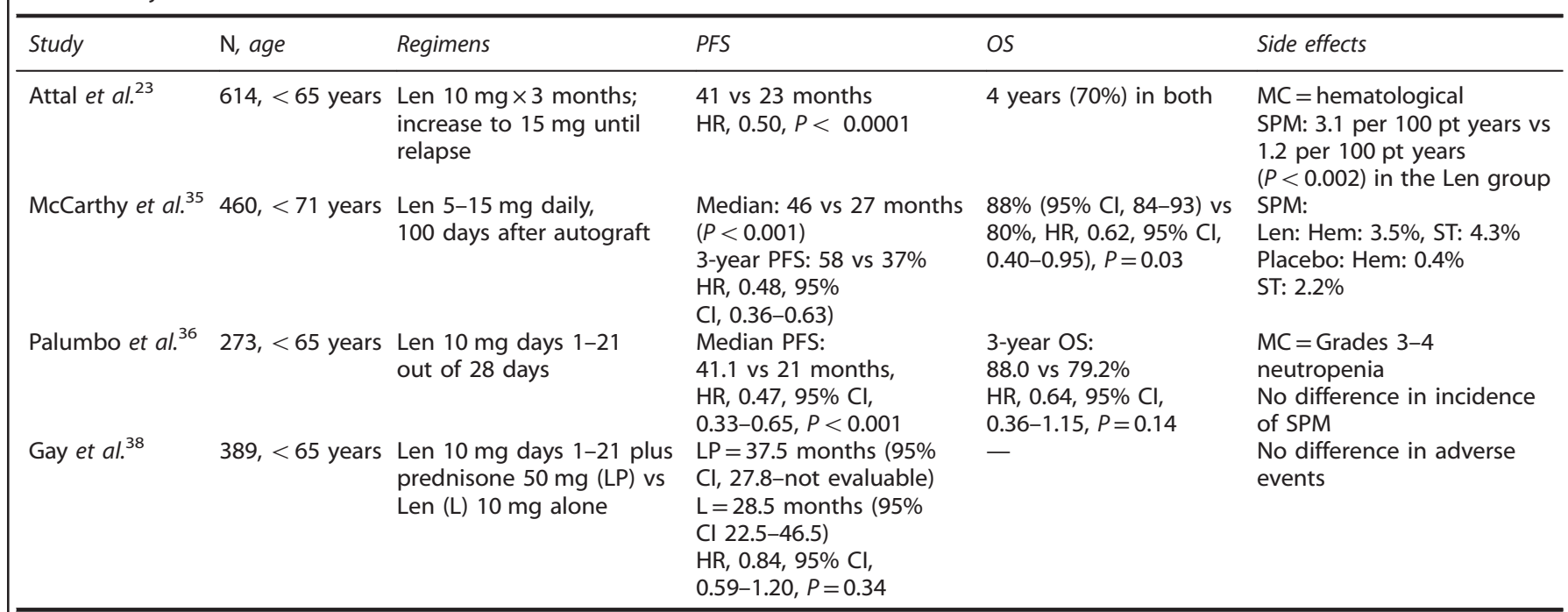

Abbreviations: $\mathrm{Cl}$, confidence interval; Hem, hematological malignancies; HR, hazard ratio; Len, lenalidomide; $\mathrm{MC}$, most common; OS, overall survival; PFS, progression-free survival; pt, patient; SPM, secondary primary malignancies; ST, solid tumor.

maintenance by Morgan et $a .^{26}$ and Kayoga et al. ${ }^{30}$ have shown a significant $O S$ benefit $(P<0.001$, hazard ratio $(\mathrm{HR})=12.3 ; 95 \%$ confidence interval $(\mathrm{Cl}), 5.5-19.0)$ and improved PFS (HR $=0.65$, $P<0.01)$ and $\mathrm{OS}(\mathrm{HR}=0.83, P=0.07)$, respectively. In clinical practice, however, long-term use of thalidomide is often limited by its toxicity. Additionally, there are some data to suggest that there may an increased risk of secondary primary malignancies (SPMs) as well. ${ }^{28}$

\section{LENALIDOMIDE MAINTENANCE}

Lenalidomide, a less toxic and more potent derivative of thalidomide with similar immunomodulatory effects, has been shown to be active in relapsed or refractory MM. ${ }^{31}$ Similarly to its parent drug, it has since been studied and shown to be effective in the front line ${ }^{32-34}$ and maintenance MM treatment setting. ${ }^{35-37}$ Owing to its better tolerability than thalidomide, it is now the preferred IMID for maintenance treatment. This is based on several large trials that have shown its efficacy post-ASCT (Table 2).

Attal et al. $^{35}$ and McCarthy et al. ${ }^{36}$ both described the use of lenalidomide maintenance post-ASCT as well tolerated and associated with statistically significant improved PFS. Attal et $\mathrm{al}^{35}$ reported in the Intergroupe Francophone du Myeloma (IFM) study 614 patients aged $<65$ years of age who underwent $\mathrm{ASCT}$, lenalidomide consolidation therapy ( $25 \mathrm{mg}$ per day on days 1-21 of 28-day cycle for 2 cycles) and were treated with either lenalidomide maintenance $(10 \mathrm{mg}$ for 3 months, followed by increase in dosing to $15 \mathrm{mg}$ if tolerated until relapse) or placebo 
maintenance. Median PFS was significantly improved in the lenalidomide maintenance group, being 41 months, as compared with 23 months in the placebo group (HR: 0.50, $P<0.0001)$. At $70 \%$, OS was similar at 4 years in both groups, though the authors note that their study was not powered to detect a difference in survival. $^{35}$ The Cancer and Leukemia Group B (CALGB) Trial reported by McCarthy et al. ${ }^{36}$ similarly showed an improvement in PFS in their study of 460 patients aged $<71$ years. Maintenance therapy with lenalidomide was started at 100 days after ASCT at $10 \mathrm{mg}$ daily dosing until disease progression. After a median follow-up of 34 months, they observed a median PFS of 46 months in the lenalidomide group compared with 27 months in the placebo group $(P<0.001)$, and a 3 -year PFS also favoring the lenalidomide group ( 58 vs $37 \%, \mathrm{HR}=0.48,95 \% \mathrm{Cl}, 0.36-0.63$ ). In contrast to the IFM study, the latter did detect a better OS in the lenalidomide group $(88 \%, 95 \% \mathrm{Cl}, 84-93$ vs $80 \%$ ( $\mathrm{HR} 0.62,95 \% \mathrm{Cl}$, $0.40-0.95, P=0.03)) .{ }^{36}$ There were some differences between the two trial protocols that could have impacted the reported outcomes. The CALGB trial induction treatments included novel agents, including thalidomide and lenalidomide, while the IFM trial induction included vincristine-based therapy plus or minus adriamycin. Neither postinduction therapy prior to ASCT nor postASCT consolidation therapy was given in the CALGB trial, while all patient received two cycles of lenalidomide consolidation in the IFM trial. Also notably, whereas no crossover was allowed in the IFM trial, crossover was allowed in the CALBG study. However, it should be noted that crossover was not allowed in placebo patients who had not progressed. ${ }^{35,36}$

Similarly to the IFM study, Palumbo et al. $^{37}$ reported in the Gruppo Italiano Malattie Emotologiches dell'Adulto (GIMEMA) trial that 273 transplant-eligible patients aged $<65$ years and who received lenalidomide maintenance, $10 \mathrm{mg}$ on days $1-21$ of each 28-day cycle until disease progression, after either ASCT or melphalan, prednisone and lenalidomide consolidation (MPR) had an improvement in PFS (median PFS 41.9 vs 21 months in the treatment group, $\mathrm{HR}=0.47,95 \% \mathrm{Cl}, 0.33-0.65, P<0.001$ ) but not in OS ( 88.0 vs $79.2 \%, \mathrm{HR}=0.64,95 \% \mathrm{Cl}, 0.36-1.15, P=0.14)$. In their study, the clinical benefit of lenalidomide maintenance therapy was independent of the type of consolidation (ASCT or MPR), and the response rates improved with maintenance, with relapse being delayed by approximately 2 years. ${ }^{37}$

Lenalidomide maintenance appears to be better tolerated than thalidomide with regards to severe, dose-limiting side effects. The most common adverse effects were hematological (specifically neutropenia) as well as dermatological. Though less common, the most striking adverse event noted in these clinical trials was the development of SPMs in patients who received lenalidomide maintenance. Both the IFM and CALGB studies showed increased risk of hematological and non-hematological second malignancies ( $2-3$ fold increased risk), whereas Palumbo et $a l^{37}$ noted no difference in SPMs. This increased risk warrants discussion with all patients who undertake maintenance therapy as part of their treatment plan post-ASCT. ${ }^{35-37}$
Although the benefits of lenalidomide maintenance after ASCT clearly outweigh the small risk of SPMs, some argue that the lack of proof of OS benefit within these clinical trials makes it arguable as to whether lenalidomide maintenance should be considered the standard of care after transplant. However, a recent metaanalysis involving 1209 patients within these 3 major randomized clinical trials of lenalidomide maintenance after ASCT (CALGB, IFM, GIMEMA) demonstrates a significantly prolonged OS compared with controls in patients with MM in all response categories. ${ }^{3}$ With a median follow-up of 6.6 years, median OS for patients who received lenalidomide maintenance was not reached compared with 82 months in the control group ( $\mathrm{HR}=0.74 ; 95 \% \mathrm{Cl}, 0.62-0.89$; log-rank $P=0.001$ ) and 5-, 6- and 7-year OS were longer in the maintenance therapy group (71 vs $66 \%, 65$ vs $58 \%$ and 62 vs $50 \%$, respectively). These data strongly suggest that lenalidomide maintenance should be discussed post-ASCT in all patients in whom it is tolerated as part of the standard of care. ${ }^{3}$ However, we must keep in mind that, at the moment, lenalidomide is not approved by the Food and Drug Administration (FDA) and European Medicines Agency (EMA).

\section{BORTEZOMIB MAINTENANCE}

Bortezomib, the first novel agent in the class of proteasome inhibitors, has been shown in early trials to have significant activity in MM. ${ }^{39}$ Like the IMIDs, it has since been integrated in standard induction therapy for many newly diagnosed patients, including those with renal impairment. ${ }^{23,40-43}$ Bortezomib garnered FDA and EMA approval for relapsed/refractory disease based on the APEX trial ${ }^{44}$ and, eventually, in 2008 for newly diagnosed disease.

In the post-ASCT setting, there are two major trials that have evaluated the efficacy of bortezomib (Table 3). The phase III HOVON-65/GMMG-HD4 Trial, reported by Sonneveld et al. ${ }^{41}$ compared vincristine, adriamycin and dexamethasone (VAD) induction vs bortezomib, adriamycin and dexamethasone (PAD) followed by ASCT and maintenance therapy consisting of either thalidomide $50 \mathrm{mg}$ daily in the VAD group or bortezomib $1.3 \mathrm{mg} /$ $\mathrm{m}^{2}$ every 2 weeks for 2 years in the PAD group. This study has been recently updated ${ }^{45}$ with a median follow-up of 91.4 months, the PFS in the PAD group was superior to that in the VAD group (34 vs 28 months, $\mathrm{HR}=0.77,95 \% \mathrm{Cl}, 0.65-0.90, P=0.001$ ). The median OS was 90 months in the PAD group compared with 83 months in the VAD group, and the restricted mean survival time was 4.8 months $(95 \% \mathrm{Cl}, 0.2-9.5, P=0.04)$ in favor of the PAD group. In the subgroup analyses of patients with renal impairment (baseline creatinine of $>2 \mathrm{mg} / \mathrm{dl}$ ), the 5 -year PFS was higher in the PAD group ( 32 vs $5 \%, P=0.001$ ) as was the 5 -year OS (66 vs $21 \%, P<0.001){ }^{45,46}$ The PFS was similar for patients who had baseline creatinine $\leqslant 2$ or $>2 \mathrm{mg} / \mathrm{dl}$, leading the investigators to conclude that use of bortezomib before ASCT and as posttransplant maintenance may overcome the negative prognostic impact of renal impairment in newly diagnosed transplant-eligible

Table 3. Major studies of bortezomib maintenance

\begin{tabular}{|c|c|c|c|c|c|}
\hline $\begin{array}{l}\text { Rosinol } \\
\text { et } \text { al. }^{43}\end{array}$ & $386,<65$ years & $\begin{array}{l}\text { IFN- } \alpha 3 \text { MU } 3 \times / \text { week vs Thal } 100 \mathrm{mg} / \text { day } \\
\text { vs Thal } 100 \mathrm{mg} / \text { day+BTZ } 1.3 \mathrm{mg} / \mathrm{m}^{2} \text { on days } \\
1,4,8 \text { and } 11 \text { every } 3 \text { months for } 3 \text { years }\end{array}$ & $\begin{array}{l}\text { 2-year PFS: } 49 \text { vs } 63 \\
\text { vs } 78 \% \text {, months } \\
(P=0.01)\end{array}$ & NS & \\
\hline
\end{tabular}


patients. ${ }^{46}$ Another analysis of the same study showed rather strikingly that patients with deletion $17 p$ (del17p13) derived the most benefit from bortezomib-containing regimens. ${ }^{47}$ In an update, both 5-year PFS and OS were superior using the bortezomib-containing regimens, $22 \%$ and $65 \%$, respectively, compared with non-bortezomib-containing regimens, $5 \%$ and $18 \%$, respectively. ${ }^{45}$ These data show that bortezomib treatment significantly improved PFS and OS in patients with del 17p, suggesting that the known adverse impact of del 17p on PFS and OS can be markedly reduced by incorporating bortezomib into the treatment and may be important for the long-term management of patients with this high-risk feature.

Rosinol et al. $^{43}$ from the Spanish Myeloma group published on 386 patients who received maintenance therapy 3 months after induction and ASCT with (1) interferon-alpha $2 \mathrm{~b} 3$ million units subcutaneously thrice weekly, (2) thalidomide $100 \mathrm{mg}$ daily or (3) thalidomide $100 \mathrm{mg}$ daily plus bortezomib $1.3 \mathrm{mg} / \mathrm{m}^{3}$ on days 1,4 , 8 and 11 every 3 months for up to 3 years. With a median followup of 24 months, an improved 2-year PFS was seen in the thalidomide+bortezomib group vs the thalidomide alone and the interferon alpha-2b groups (78 vs 63 vs $49 \%, P=0.01$ ). No difference in OS was detected. ${ }^{43}$

\section{SUMMARY OF AVAILABLE TRIALS}

Most of the data to support maintenance therapy in the after autologous stem cell setting are related to the use of the oral IMIDS, thalidomide and lenalidomide. Long-term thalidomide therapy, however, appears to be limited by its significant side effect profile, which includes dose-limiting peripheral neuropathy requiring cessation of therapy in a significant number of patients. Lenalidomide, its more potent analog, has several large phase III studies and a recent meta-analysis strongly supporting its use in post-ASCT maintenance. It has been shown to delay progression by approximately 2 years as well as have a significant OS benefit. ${ }^{3,35-37}$ However, the concern with lenalidomide in the maintenance setting has been the increased risk of SPMs in patients who received lenalidomide compared with placebo, which is an important consideration particularly in the setting of most patients having prior exposure to high-dose melphalan therapy. The proteasome inhibitor bortezomib is also well tolerated after transplant and may be preferred in the event of renal impairment and high-risk features, such as the 17p deletion. No increased risk of SPMs was seen in bortezomib trials, but its injectable form could be a limit for long-term maintenance therapy. However, subcutaneous administration is well tolerated ${ }^{48}$ and home administration is feasible ${ }^{49}$ and could further improve patients' acceptance, particularly in the setting of a long-term maintenance therapy. Recently, an oral proteasome inhibitors, namely ixazomib, have emerged as efficacious for $M M$ in the relapsed, refractory setting ${ }^{50}$ that is also being investigated for maintenance use.

There are limited data on the impact of long-term maintenance therapy on the quality of life in patients with MM, and this needs to be further investigated in future trials. Stewart et al. ${ }^{28}$ did note in their study that long-term maintenance with thalidomide appeared to adversely impact patient's quality of life and much of it was attributed to the side effect profile of the drug itself.

\section{NEWER AGENTS}

Proteasome inhibitors

Ixazomib is a new oral, second-generation peptide boronic acid proteasome inhibitor that acts similarly to bortezomib in that it targets nuclear factor- $\mathrm{KB}$ and has antiangiogenic properties ${ }^{51}$ and has been shown to have strong preclinical efficacy. ${ }^{52,53}$ Similarly to its IMID counterparts, one of the attractive features of ixazomib is its oral administration. It has been shown in early phase I/II trials, as part of an all oral induction regimen of ixazomib, lenalidomide and dexamethasone, to be well tolerated and active as upfront treatment for newly diagnosed patients. ${ }^{54}$ Recently, a large double-blind, placebo-controlled phase III clinical trial with 722 patients was published that demonstrated improved PFS in patients with relapsed/refractory disease, which led to the FDA approval for this indication. Patients who received ixazomib in addition to lenalidomide and dexamethasone had a PFS of 20.6 months compared with just 14 months (HR 0.74, $P=0.01$ ) for those who received lenalidomide and dexamethasone alone. This difference was seen in all subgroups of patients, including those with high-risk cytogenetics. At 23 months, the median OS was not reached in either group. In patients who received ixazomib, there was limited additional toxicity with patient-reported quality of life similar in both groups. ${ }^{50}$ Several clinical trials are ongoing investigating its use alone or in combination with lenalidomide in the posttransplant maintenance setting (Table 4).

Carfilzomib is a next-generation irreversible proteasome inhibitor that binds selectively and irreversibly to the constitutive proteasome and immunoproteasome. Carfilzomib is equally potent but more selective for the chymotrypsine-like activity of the proteasome than bortezomib and preclinical data have shown efficacy of carfilzomib in hematological malignancies, with a higher cytotoxicity compared with bortezomib. ${ }^{55}$ Carfilzomib monotherapy has therefore been shown to be effective in relapse MM in early phase I/II trial. ${ }^{56,57}$ Recently, a large randomized phase III clinical trial with 792 patients reported that the addition of carfilzomib to the combination of lenalidomide and dexamethasone improved PFS in patients with relapsed/refractory disease, which led to the FDA and EMA approval for this indication. ${ }^{58}$ Carfilzomib is now being evaluated as part of the combination therapy for first-line MM treatment in patients eligible to ASCT. Bringhen et $a .^{59}$ recently reported the results of a phase I/II study evaluating weekly carfilzomib, cyclophosphamide and dexamethasone followed by maintenance with weekly carfilzomib in elderly patients with MM. Carfilzomib maintenance appears to be safe and effective with an improvement of complete remission rate from $12 \%$ to $40 \%$. Overall, results from carfilzomib use in relapse/refractory $\mathrm{MM}$ and in the non-transplant maintenance setting suggest that posttransplant maintenance therapy using carfilzomib may be relevant, despite its intravenous administration. Carfilzomib is currently evaluated in this setting in several clinical trials (Table 4).

\section{MONOCLONAL ANTIBODIES}

Monoclonal antibodies directed against targets expressed on myeloma cells have emerged as an effective treatment for MM. Among others, elotuzumab, which targets SLAMF-7, and daratumumab, which targets CD38, are the monoclonal antibodies with the most advanced clinical development. Elotuzumab and daratumumab are approved by the FDA and EMA for relapsed/ refractory MM. A large randomized phase III clinical trial with 646 patients recently reported that the addition of elotuzumab to lenalidomide and dexamethasone in relapse /refractory MM was associated with an improved PFS (19.4 vs 14.9 months in the control group; $P<0.001){ }^{60}$ Regarding daratumumab, two phase $\mathrm{I} / \mathrm{Il}$ studies reported that the use of daratumumab monotherapy in relapsed/refractory $\mathrm{MM}$ was associated with overall response rate of $36 \%$ and $29.2 \%$ respectively. ${ }^{61,62}$ More recently, two large randomized phase III studies evaluated the addition of daratumumab to the combination of bortezomib plus dexamethasone ${ }^{63}$ or lenalidomide and dexamethasone ${ }^{64}$ in relapse/refractory MM. Both studies have shown that the addition of daratumumab improved PFS, time to progression and overall response rate. ${ }^{63,64}$ Elotuzumab and daratumumab are now being evaluated for MM first-line treatment. A prospective randomized phase III study is ongoing evaluating the combination of bortezomib, thalidomide 
Table 4. Ongoing maintenance studies after ASCT with newer agents

\begin{tabular}{|c|c|c|c|}
\hline ClinicalTrial.gov identifier & Phase & Arms & \\
\hline \multicolumn{4}{|c|}{ Ixazomid-based maintenance } \\
\hline NCT02504359 & I & Ixazomib & 2 years \\
\hline NCT02253316 & II & Lenalidomide vs ixazomib & 3 years \\
\hline NCT02619682 & II & Alternating lenalidomide+ixazomib & 2 years \\
\hline NCT02168101 ${ }^{\mathrm{a}}$ & II & Ixazomib & 6 months \\
\hline NCT01936532 & II & Ixazomib & 1 year \\
\hline NCT02181413 & III & Ixazomib vs placebo & 2 years \\
\hline NCT02406144 & III & Lenalidomide vs lenalidomide+ixazomib & $\begin{array}{l}2 \text { years in MRD- } \\
5 \text { years in MRD+ }\end{array}$ \\
\hline \multicolumn{4}{|c|}{ Carfilzomid-based maintenance } \\
\hline NCT02315716 & II & Carfilzomib & 18 months \\
\hline NCT01816971 ${ }^{\mathrm{a}}$ & II & Lenalidomide+carfilzomib+dexamethasone & 10 months \\
\hline NCT02659293 & III & Lenalidomide vs lenalidomide+carfilzomib+dexamethasone & NA \\
\hline \multicolumn{4}{|c|}{ Elotuzumab-based maintenance } \\
\hline NCT02655458 & 1 & Lenalidomide+elotuzumab & 1 year \\
\hline NCT02843074 & II & Elotuzumab & 2 years \\
\hline NCT02420860 & II & Lenalidomide+elotuzumab & NA \\
\hline NCT02375555 & ॥ & Lenalidomide+bortezomib+elotuzumab & NA \\
\hline NCT02495922 & III & Lenalidomide vs lenalidomide+elotuzumab & 2 years \\
\hline \multicolumn{4}{|c|}{ Daratumumab-based maintenance } \\
\hline NCT02541383 & III & Daratumumab vs observation & 2 years \\
\hline \multicolumn{4}{|c|}{ Vorinostat-based maintenance } \\
\hline NCT00729118 & I & Lenalidomide+vorinostat & Until progression \\
\hline NCT00839956 & II & Bortezomib+vorinostat & 1 year \\
\hline NCT01554852 $2^{\mathrm{b}}$ & III & Observation vs lenalidomide vs lenalidomide+vorinostat & Until progression \\
\hline \multicolumn{4}{|c|}{ Panobinostat-based maintenance } \\
\hline NCT01440582 & I & Lenalidomide+panobinostat & NA \\
\hline NCT02145715 & I-II & Panobinostat & 1 year \\
\hline NCT02722941 & II & Panobinostat & NÁ \\
\hline \multirow[t]{2}{*}{ NCT02720510 } & II & Lenalidomide & 3 years \\
\hline & & Lenalidomide+panobinostat & \\
\hline NCT02802163 & II & Lenalidomide+panobinostat & $\begin{array}{l}\text { Until progression } \\
1 \text { year }\end{array}$ \\
\hline
\end{tabular}

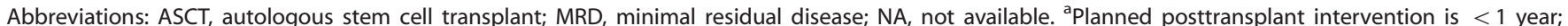
however, this intervention is referred as maintenance in the clinical trial. ${ }^{b}$ Maintenance will be evaluated after autologous hematopoietic stem cell transplantation and in non-transplanted patients.

and dexamethasone with or without daratumumab, before ASCT, followed by a maintenance therapy with daratumumab (NCT025411383). Similarly, elotuzumab-based maintenance after ASCT is currently investigated in several clinical trials (Table 4).

Histone deacetylase inhibitors (HDAC-I)

HDAC-I have recently been shown to be effective in treatment for MM. Their mechanism of action is via targeting of epigeneticsilencing mechanisms, increasing the susceptibility of tumor cells to immune-mediated killing and inhibition of cytokine release to disrupt the tumor microenvironment. ${ }^{65-68}$ Several trials have since shown the efficacy of the non-specific HDAC-I, vorinostat, in combination with conventional drug therapy in relapsed/refractory MM. ${ }^{68-72}$ Recently, a phase I study showed the tolerability of the combination of lenalidomide and vorinostat as post-ASCT maintenance therapy for MM, which showed an improvement in posttransplant response in 7 out of the 16 patients. $^{73}$

Another HDAC-I, panobinostat, has also shown to have efficacy in preclinical studies. ${ }^{74,75}$ A large phase III clinical trial demonstrated that, when panobinostat was added to bortezomib and dexamethasone, it led to improvements in $\mathrm{PFS}^{76}$ as well as induced responses in heavily pretreated bortezomib-refractory patients. ${ }^{77}$ There are minimal data in the posttransplant maintenance setting, although a series of cases has been reported using panobinostat as a maintenance drug in patients with relapsed disease. $^{78}$

Both HDAC-I drugs are attractive options due to their oral bioavailability and appear to be well tolerated in early clinical trials. Further investigations are ongoing to ascertain their role in the posttransplant maintenance setting (Table 4).

\section{SUMMARY}

Maintenance therapy in $\mathrm{MM}$ is an integral part of improving patient outcome after autologous hematopoietic stem cell transplantation due to its role in suppression of residual disease. ASCT remains the standard of care for fit, eligible, newly diagnosed patients after induction therapy. Although, its wider use has been tempered by the recognition of a small increased risk of SPMs, the results of the most recent meta-analysis showing a significant OS benefit in patients treated with lenalidomide maintenance argue in favor of establishing lenalidomide maintenance as the standard of care in the post-ASCT setting, provided approval is granted by the FDA and EMA. ${ }^{3}$ Similarly, large trial data support the use of bortezomib use in posttransplant maintenance, particularly in high-risk patients.

Second-generation proteasome inhibitors, monoclonal antibodies and HDAC-I provides the scope for them to be studied in the posttransplant maintenance setting, particularly in relation to tolerability, and whether serious side effects such as SPMs are part of their profile. Oral agents, including ixazomib, vorinostat and panobinostat, are particularly interesting in this setting. As patients are living longer with $\mathrm{MM}$, strategies to prolong their survival along with ensuring good quality of life are important in optimizing patient care. 


\section{CONFLICT OF INTEREST}

MM received lectures' honoraria and/or research support from Janssen, Celgene, Amgen, Takeda, Novartis and Bristol-Myers whose products are discussed in this work. The other authors declare no conflict of interest.

\section{REFERENCES}

1 Kumar SK, Rajkumar SV, Dispenzieri A, Lacy MQ, Hayman SR, Buadi FK et al. Improved survival in multiple myeloma and the impact of novel therapies. Blood 2008; 111: 2516-2520.

2 Barlogie B, Attal M, Crowley J, van Rhee F, Szymonifka J, Moreau P et al. Long-term follow-up of autotransplantation trials for multiple myeloma: update of protocols conducted by the intergroupe francophone du myelome, southwest oncology group, and university of arkansas for medical sciences. J Clin Oncol 2010; 28: 1209-1214.

3 Attal M, Palumbo A, Holstein SA, Lauwers-Cances V, Petrucci MT, Richardson PG et al. Lenalidomide (LEN) maintenance (MNTC) after high-dose melphalan and autologous stem cell transplant (ASCT) in multiple myeloma (MM): a metaanalysis (MA) of overall survival (OS). ASCO Meeting Abstr 2016; 34: 8001.

4 Barlogie B, Tricot GJ, van Rhee F, Angtuaco E, Walker R, Epstein J et al. Long-term outcome results of the first tandem autotransplant trial for multiple myeloma. $\mathrm{Br} J$ Haematol 2006; 135: 158-164.

5 Child JA, Morgan GJ, Davies FE, Owen RG, Bell SE, Hawkins $\mathrm{K}$ et al. High-dose chemotherapy with hematopoietic stem-cell rescue for multiple myeloma. $\mathrm{N}$ Engl J Med 2003; 348: 1875-1883.

6 Attal M, Harousseau JL, Stoppa AM, Sotto JJ, Fuzibet JG, Rossi JF et al. A prospective, randomized trial of autologous bone marrow transplantation and chemotherapy in multiple myeloma. Intergroupe Francais du Myelome. $N$ Engl J Med 1996; 335: 91-97.

7 Attal M, Lauwers-Cances V, Hulin C, Facon T, Caillot D, Escoffre M et al. Autologous transplantation for multiple myeloma in the era of new drugs: a phase III study of the Intergroupe Francophone Du Myelome (IFM/DFCl 2009 trial). Blood 2015; 126: 391-391.

8 Cavo M, Palumbo A, Zweegman S, Dimopoulos MA, Hajek R, Pantani $L$ et al. Upfront autologous stem cell transplantation (ASCT) versus novel agent-based therapy for multiple myeloma (MM): A randomized phase 3 study of the European Myeloma Network (EMN02/HO95 MM trial). ASCO Meeting Abstr 2016; 34: 8000.

9 Mohty M, Richardson PG, McCarthy PL, Attal M. Consolidation and maintenance therapy for multiple myeloma after autologous transplantation: where do we stand? Bone Marrow Transplant 2015; 50: 1024-1029.

10 Kapoor P, Kumar SK, Dispenzieri A, Lacy MQ, Buadi F, Dingli D et al. Importance of achieving stringent complete response after autologous stem-cell transplantation in multiple myeloma. J Clin Oncol 2013; 31: 4529-4535.

11 Rawstron AC, Child JA, de Tute RM, Davies FE, Gregory WM, Bell SE et al. Minimal residual disease assessed by multiparameter flow cytometry in multiple myeloma: impact on outcome in the Medical Research Council Myeloma IX Study. J Clin Oncol 2013; 31: 2540-2547.

12 de Tute RM, Rawstron AC, Gregory WM, Child JA, Davies FE, Bell SE et al. Minimal residual disease following autologous stem cell transplant in myeloma: impact on outcome is independent of induction regimen. Haematologica 2016; 101: e69-e71.

13 Martinez-Lopez J, Lahuerta JJ, Pepin F, Gonzalez M, Barrio S, Ayala R et al. Prognostic value of deep sequencing method for minimal residual disease detection in multiple myeloma. Blood 2014; 123: 3073-3079.

14 Rawstron AC, Gregory WM, de Tute RM, Davies FE, Bell SE, Drayson MT et al. Minimal residual disease in myeloma by flow cytometry: independent prediction of survival benefit per log reduction. Blood 2015; 125: 1932-1935.

15 Myeloma Trialists' Collaborative Group. Interferon as therapy for multiple myeloma: an individual patient data overview of 24 randomized trials and 4012 patients. Br J Haematol 2001; 113: 1020-1034.

16 Alexanian R, Weber D, Dimopoulos M, Delasalle K, Smith TL. Randomized trial of alpha-interferon or dexamethasone as maintenance treatment for multiple myeloma. Am J Hematol 2000; 65: 204-209.

17 Belch A, Shelley W, Bergsagel D, Wilson K, Klimo P, White D et al. A randomized trial of maintenance versus no maintenance melphalan and prednisone in responding multiple myeloma patients. Br J Cancer 1988; 57: 94-99.

18 Berenson JR, Crowley JJ, Grogan TM, Zangmeister J, Briggs AD, Mills GM et al. Maintenance therapy with alternate-day prednisone improves survival in multiple myeloma patients. Blood 2002; 99: 3163-3168.

19 Fritz E, Ludwig $\mathrm{H}$. Interferon-alpha treatment in multiple myeloma: meta-analysis of 30 randomised trials among 3948 patients. Ann Oncol 2000; 11: 1427-1436.

20 Shustik C, Belch A, Robinson S, Rubin SH, Dolan SP, Kovacs MJ et al. A randomised comparison of melphalan with prednisone or dexamethasone as induction therapy and dexamethasone or observation as maintenance therapy in multiple myeloma: NCIC CTG MY.7. Br J Haematol 2007; 136: 203-211.
21 Singhal S, Mehta J, Desikan R, Ayers D, Roberson P, Eddlemon P et al. Antitumor activity of thalidomide in refractory multiple myeloma. $N$ Engl J Med 1999; 341: 1565-1571.

22 Rajkumar SV, Hayman S, Gertz MA, Dispenzieri A, Lacy MQ, Greipp PR et al. Combination therapy with thalidomide plus dexamethasone for newly diagnosed myeloma. J Clin Oncol 2002; 20: 4319-4323.

23 Cavo M, Tacchetti P, Patriarca F, Petrucci MT, Pantani L, Galli M et al. Bortezomib with thalidomide plus dexamethasone compared with thalidomide plus dexamethasone as induction therapy before, and consolidation therapy after, double autologous stem-cell transplantation in newly diagnosed multiple myeloma: a randomised phase 3 study. Lancet 2010; 376: 2075-2085.

24 Attal M, Harousseau JL, Leyvraz S, Doyen C, Hulin C, Benboubker L et al. Maintenance therapy with thalidomide improves survival in patients with multiple myeloma. Blood 2006; 108: 3289-3294.

25 Barlogie B, Tricot G, Anaissie E, Shaughnessy J, Rasmussen E, van Rhee F et al. Thalidomide and hematopoietic-cell transplantation for multiple myeloma. $\mathrm{N}$ Engl J Med 2006; 354: 1021-1030.

26 Morgan GJ, Gregory WM, Davies FE, Bell SE, Szubert AJ, Brown JM et al. The role of maintenance thalidomide therapy in multiple myeloma: MRC Myeloma IX results and meta-analysis. Blood 2012; 119: 7-15.

27 Lokhorst HM, van der Holt B, Zweegman S, Vellenga E, Croockewit S, van Oers MH et al. A randomized phase 3 study on the effect of thalidomide combined with adriamycin, dexamethasone, and high-dose melphalan, followed by thalidomide maintenance in patients with multiple myeloma. Blood 2010; 115: 1113-1120.

28 Stewart AK, Trudel S, Bahlis NJ, White D, Sabry W, Belch A et al. A randomized phase 3 trial of thalidomide and prednisone as maintenance therapy after ASCT in patients with MM with a quality-of-life assessment: the National Cancer Institute of Canada Clinicals Trials Group Myeloma 10 Trial. Blood 2013; 121: 1517-1523.

29 Maiolino A, Hungria VT, Garnica M, Oliveira-Duarte G, Oliveira LC, Mercante DR et al. Thalidomide plus dexamethasone as a maintenance therapy after autologous hematopoietic stem cell transplantation improves progression-free survival in multiple myeloma. Am J Hematol 2012; 87: 948-952.

30 Kagoya $Y$, Nannya Y, Kurokawa M. Thalidomide maintenance therapy for patients with multiple myeloma: meta-analysis. Leuk Res 2012; 36: 1016-1021.

31 Schey SA, Fields P, Bartlett JB, Clarke IA, Ashan G, Knight RD et al. Phase I study of an immunomodulatory thalidomide analog, CC-4047, in relapsed or refractory multiple myeloma. J Clin Oncol 2004; 22: 3269-3276.

32 Rajkumar SV, Hayman SR, Lacy MQ, Dispenzieri A, Geyer SM, Kabat B et al. Combination therapy with lenalidomide plus dexamethasone (Rev/Dex) for newly diagnosed myeloma. Blood 2005; 106: 4050-4053.

33 Dimopoulos M, Spencer A, Attal M, Prince HM, Harousseau JL, Dmoszynska A et al. Lenalidomide plus dexamethasone for relapsed or refractory multiple myeloma. $N$ Engl J Med 2007; 357: 2123-2132.

34 Weber DM, Chen C, Niesvizky R, Wang M, Belch A, Stadtmauer EA et al. Lenalidomide plus dexamethasone for relapsed multiple myeloma in North America. N Engl J Med 2007; 357: 2133-2142.

35 Attal M, Lauwers-Cances V, Marit G, Caillot D, Moreau P, Facon T et al. Lenalidomide maintenance after stem-cell transplantation for multiple myeloma. $N$ Engl J Med 2012; 366: 1782-1791.

36 McCarthy PL, Owzar K, Hofmeister CC, Hurd DD, Hassoun H, Richardson PG et al. Lenalidomide after stem-cell transplantation for multiple myeloma. $\mathrm{N}$ Engl J Med 2012; 366: 1770-1781.

37 Palumbo A, Cavallo F, Gay F, Di Raimondo F, Ben Yehuda D, Petrucci MT et al. Autologous transplantation and maintenance therapy in multiple myeloma. N Engl J Med 2014; 371: 895-905.

38 Gay F, Oliva S, Petrucci MT, Conticello C, Catalano L, Corradini P et al. Chemotherapy plus lenalidomide versus autologous transplantation, followed by lenalidomide plus prednisone versus lenalidomide maintenance, in patients with multiple myeloma: a randomised, multicentre, phase 3 trial. Lancet Oncol 2015; 16: 1617-1629.

39 Orlowski RZ, Stinchcombe TE, Mitchell BS, Shea TC, Baldwin AS, Stahl S et al. Phase I trial of the proteasome inhibitor PS-341 in patients with refractory hematologic malignancies. J Clin Oncol 2002; 20: 4420-4427.

40 Harousseau JL, Attal M, Avet-Loiseau H, Marit G, Caillot D, Mohty M et al. Bortezomib plus dexamethasone is superior to vincristine plus doxorubicin plus dexamethasone as induction treatment prior to autologous stem-cell transplantation in newly diagnosed multiple myeloma: results of the IFM 2005-01 phase III trial. J Clin Oncol 2010; 28: 4621-4629.

41 Sonneveld P, Schmidt-Wolf IG, van der Holt B, El Jarari L, Bertsch U, Salwender H et al. Bortezomib induction and maintenance treatment in patients with newly diagnosed multiple myeloma: results of the randomized phase III HOVON-65/ GMMG-HD4 trial. J Clin Oncol 2012; 30: 2946-2955.

42 Moreau P, Avet-Loiseau H, Facon T, Attal M, Tiab M, Hulin C et al. Bortezomib plus dexamethasone versus reduced-dose bortezomib, thalidomide plus dexametha- 
sone as induction treatment before autologous stem cell transplantation in newly diagnosed multiple myeloma. Blood 2011; 118: 5752-5758, quiz 5982.

43 Rosinol L, Oriol A, Teruel Al, Hernandez D, Lopez-Jimenez J, de la Rubia J et al. Superiority of bortezomib, thalidomide, and dexamethasone (VTD) as induction pretransplantation therapy in multiple myeloma: a randomized phase 3 PETHEMA/GEM study. Blood 2012; 120: 1589-1596.

44 Richardson PG, Sonneveld P, Schuster MW, Irwin D, Stadtmauer EA, Facon T et al. Bortezomib or high-dose dexamethasone for relapsed multiple myeloma. $N$ Engl J Med 2005; 352: 2487-2498.

45 Sonneveld P, Salwender H-J, Van Der Holt B, el Jarari L, Bertsch U, Blau IW et al. Bortezomib induction and maintenance in patients with newly diagnosed multiple myeloma: long-term follow-up of the HOVON-65/GMMG-HD4 Trial. Blood 2015; 126: 27-27.

46 Scheid C, Sonneveld P, Schmidt-Wolf IG, van der Holt B, el Jarari L, Bertsch U et al. Bortezomib before and after autologous stem cell transplantation overcomes the negative prognostic impact of renal impairment in newly diagnosed multiple myeloma: a subgroup analysis from the HOVON-65/GMMG-HD4 trial. Haematologica 2014; 99: 148-154.

47 Neben K, Lokhorst HM, Jauch A, Bertsch U, Hielscher T, van der Holt B et al. Administration of bortezomib before and after autologous stem cell transplantation improves outcome in multiple myeloma patients with deletion 17p. Blood 2012; 119: 940-948.

48 Moreau P, Pylypenko H, Grosicki S, Karamanesht I, Leleu X, Grishunina M et al. Subcutaneous versus intravenous administration of bortezomib in patients with relapsed multiple myeloma: a randomised, phase 3, non-inferiority study. Lancet Oncol 2011; 12: 431-440.

49 Lassalle A, Thomare P, Fronteau C, Mahe B, Jube C, Blin N et al. Home administration of bortezomib in multiple myeloma is cost-effective and is preferred by patients compared with hospital administration: results of a prospective singlecenter study. Ann Oncol 2016; 27: 314-318.

50 Moreau P, Masszi T, Grzasko N, Bahlis NJ, Hansson M, Pour L et al. Oral ixazomib, lenalidomide, and dexamethasone for multiple myeloma. N Engl J Med 2016; 374: 1621-1634.

51 Chauhan D, Tian Z, Zhou B, Kuhn D, Orlowski R, Raje N et al. In vitro and in vivo selective antitumor activity of a novel orally bioavailable proteasome inhibitor MLN9708 against multiple myeloma cells. Clin Cancer Res 2011; 17: 5311-5321.

52 Kupperman E, Lee EC, Cao Y, Bannerman B, Fitzgerald M, Berger A et al. Evaluation of the proteasome inhibitor MLN9708 in preclinical models of human cancer. Cancer Res 2010; 70: 1970-1980.

53 Lee EC, Fitzgerald M, Bannerman B, Donelan J, Bano K, Terkelsen J et al. Antitumor activity of the investigational proteasome inhibitor MLN9708 in mouse models of B-cell and plasma cell malignancies. Clin Cancer Res 2011; 17: 7313-7323.

54 Kumar SK, Berdeja JG, Niesvizky R, Lonial S, Laubach JP, Hamadani M et al. Safety and tolerability of ixazomib, an oral proteasome inhibitor, in combination with lenalidomide and dexamethasone in patients with previously untreated multiple myeloma: an open-label phase 1/2 study. Lancet Oncol 2014; 15: 1503-1512.

55 Kuhn DJ, Chen Q, Voorhees PM, Strader JS, Shenk KD, Sun CM et al. Potent activity of carfilzomib, a novel, irreversible inhibitor of the ubiquitin-proteasome pathway, against preclinical models of multiple myeloma. Blood 2007; 110: 3281-3290.

56 Siegel DS, Martin T, Wang M, Vij R, Jakubowiak AJ, Lonial S et al. A phase 2 study of single-agent carfilzomib (PX-171-003-A1) in patients with relapsed and refractory multiple myeloma. Blood 2012; 120: 2817-2825.

57 Jagannath S, Vij R, Stewart AK, Trudel S, Jakubowiak AJ, Reiman T et al. An openlabel single-arm pilot phase II study (PX-171-003-A0) of low-dose, single-agent carfilzomib in patients with relapsed and refractory multiple myeloma. Clin Lymphoma Myeloma Leuk 2012; 12: 310-318.

58 Stewart AK, Rajkumar SV, Dimopoulos MA, Masszi T, Spicka I, Oriol A et al. Carfilzomib, lenalidomide, and dexamethasone for relapsed multiple myeloma. N Engl J Med 2015; 372: 142-152.

59 Bringhen S, De Paoli L, Larocca A, Ballanti S, Gentilini F, Liberati AM et al. Weekly carfilzomib, cyclophosphamide and dexamethasone (WKCYD) followed by maintenance with weekly carfilzomib (WK) in elderly patients with newly diagnosed multiple myeloma (NDMM). Haematologica 2016; 101: 1-881.

60 Lonial S, Dimopoulos M, Palumbo A, White D, Grosicki S, Spicka I et al. Elotuzumab therapy for relapsed or refractory multiple myeloma. N Engl J Med 2015; 373: 621-631.

61 Lokhorst HM, Plesner T, Laubach JP, Nahi H, Gimsing P, Hansson M et al. Targeting CD38 with daratumumab monotherapy in multiple myeloma. N Engl J Med 2015; 373: 1207-1219.

62 Lonial S, Weiss BM, Usmani SZ, Singhal S, Chari A, Bahlis NJ et al. Daratumumab monotherapy in patients with treatment-refractory multiple myeloma (SIRIUS): an open-label, randomised, phase 2 trial. Lancet 2016; 387: 1551-1560.
63 Palumbo A, Chanan-Khan AAA, Weisel K, Nooka AK, Masszi T, Beksac M et al. Phase III randomized controlled study of daratumumab, bortezomib, and dexamethasone (DVd) versus bortezomib and dexamethasone (Vd) in patients (pts) with relapsed or refractory multiple myeloma (RRMM): CASTOR study. ASCO Meeting Abstr 2016; 34: LBA4.

64 Dimopoulos M, Oriol A, Nahi N, San Miguel J, Bahlis N, Rabin N et al. An openlabel, randomised phase 3 study of daratumumab, lenalidomide, and dexamethasone (DRD) versus lenalidomide and dexamethasone (RD) in relapsed or refractory multiple myeloma (RRMM): POLLUX. Haematologica 2016; 101: $1-881$.

65 Skov S, Pedersen MT, Andresen L, Straten PT, Woetmann A, Odum N. Cancer cells become susceptible to natural killer cell killing after exposure to histone deacetylase inhibitors due to glycogen synthase kinase-3-dependent expression of MHC class I-related chain A and B. Cancer Res 2005; 65: 11136-11145.

66 Gialitakis M, Kretsovali A, Spilianakis C, Kravariti L, Mages J, Hoffmann R et al. Coordinated changes of histone modifications and HDAC mobilization regulate the induction of MHC class II genes by Trichostatin A. Nucleic Acids Res 2006; 34: 765-772.

67 Leoni F, Zaliani A, Bertolini G, Porro G, Pagani P, Pozzi P et al. The antitumor histone deacetylase inhibitor suberoylanilide hydroxamic acid exhibits antiinflammatory properties via suppression of cytokines. Proc Natl Acad Sci USA 2002; 99: $2995-3000$.

68 Richardson P, Mitsiades C, Colson K, Reilly E, McBride L, Chiao J et al. Phase I trial of oral vorinostat (suberoylanilide hydroxamic acid, SAHA) in patients with advanced multiple myeloma. Leuk Lymphoma 2008; 49: 502-507.

69 Badros A, Burger AM, Philip S, Niesvizky R, Kolla SS, Goloubeva O et al. Phase I study of vorinostat in combination with bortezomib for relapsed and refractory multiple myeloma. Clin Cancer Res 2009; 15: 5250-5257.

70 Weber DM, Graef T, Hussein M, Sobecks RM, Schiller GJ, Lupinacci L et al. Phase I trial of vorinostat combined with bortezomib for the treatment of relapsing and/or refractory multiple myeloma. Clin Lymphoma Myeloma Leuk 2012; 12: 319-324.

71 Dimopoulos M, Siegel DS, Lonial S, Qi J, Hajek R, Facon T et al. Vorinostat or placebo in combination with bortezomib in patients with multiple myeloma (VANTAGE 088): a multicentre, randomised, double-blind study. Lancet Oncol 2013; 14: 1129-1140.

72 Siegel DS, Richardson P, Dimopoulos M, Moreau P, Mitsiades C, Weber D et al. Vorinostat in combination with lenalidomide and dexamethasone in patients with relapsed or refractory multiple myeloma. Blood Cancer J 2014; 4: e202.

73 Sborov DW, Benson DM, Williams N, Huang Y, Bowers MA, Humphries $\mathrm{K}$ et al. Lenalidomide and vorinostat maintenance after autologous transplant in multiple myeloma. Br J Haematol 2015; 171: 74-83.

74 Maiso P, Carvajal-Vergara X, Ocio EM, Lopez-Perez R, Mateo G, Gutierrez N et al. The histone deacetylase inhibitor LBH589 is a potent antimyeloma agent that overcomes drug resistance. Cancer Res 2006; 66: 5781-5789.

75 Catley L, Weisberg E, Kiziltepe T, Tai YT, Hideshima T, Neri P et al. Aggresome induction by proteasome inhibitor bortezomib and alpha-tubulin hyperacetylation by tubulin deacetylase (TDAC) inhibitor LBH589 are synergistic in myeloma cells. Blood 2006; 108: 3441-3449.

76 San-Miguel JF, Hungria VT, Yoon SS, Beksac M, Dimopoulos MA, Elghandour A et al. Panobinostat plus bortezomib and dexamethasone versus placebo plus bortezomib and dexamethasone in patients with relapsed or relapsed and refractory multiple myeloma: a multicentre, randomised, double-blind phase 3 trial. Lancet Oncol 2014; 15: 1195-1206.

77 Richardson PG, Schlossman RL, Alsina M, Weber DM, Coutre SE, Gasparetto C et al. PANORAMA 2: panobinostat in combination with bortezomib and dexamethasone in patients with relapsed and bortezomib-refractory myeloma. Blood 2013; 122: 2331-2337.

78 Ocio EM, Davila J, Caballero JC, Alonso S, de la Calle VG, Garcia-Sanz R et al. Evidence of long-term disease control with panobinostat maintenance in patients with relapsed multiple myeloma. Haematologica 2015; 100: e289-e291.

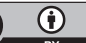

This work is licensed under a Creative Commons Attribution 4.0 International License. The images or other third party material in this article are included in the article's Creative Commons license, unless indicated otherwise in the credit line; if the material is not included under the Creative Commons license, users will need to obtain permission from the license holder to reproduce the material. To view a copy of this license, visit http://creativecommons.org/licenses/ by/4.0/

(c) The Author(s) 2017 